\title{
Designing External Knowledge \\ Communication in a Research Network \\ The Case of Sustainable Land \\ Management
}

\author{
Thomas Köhler, Thomas Weith, Sabrina Herbst, and Nadin Gaasch
}

\begin{abstract}
Designing knowledge communication with external partners is a core activity of research networks. In science, such communication has been addressed only recently and is still considered as non-academic activity. Successful communication with practitioners, that is knowledge transfer, is a crucial factor for effective research. In the age of online communication, this requires special attention and skills, for example related to social media communication. Based on our own empirical results derived from interviews, the authors identify what factors affect the communication process and how the design of communication content may be influenced.

To do so, successful examples of communication with external stakeholders are presented. For the theoretical basis, science communication, knowledge communication, knowledge management, and knowledge transfer were selected and consolidated. Although the findings stem from a research network specializing in sustainable land management, they can be transferred to other academic collaborations. Our results indicate that external communication is effective when knowledge has been transferred between academics and practitioners.
\end{abstract}

Keywords Research network - Knowledge management • Open science • Qualitative research $\cdot$ Land management

\footnotetext{
T. Köhler

Faculty of Education/Institute for Vocational Education, TU Dresden, Dresden, Germany

e-mail: thomas.koehler@tu-dresden.de

T. Weith

Leibniz Centre for Agricultural Landscape Research, Müncheberg, Germany

e-mail: thomas.weith@zalf.de

S. Herbst $(\bowtie)$

Media Centre, TU Dresden, Dresden, Germany

e-mail: sabrina.herbst@tu-dresden.de

N. Gaasch

TU Berlin, Office of the First Vice President for Research, Appointment Strategy, Knowledge \&

Technology Transfer, Berlin, Germany

e-mail: nadin.gaasch@tu-berlin.de
} 


\section{Background: Theory and Project}

The results presented in the article are developed in the context of funding measures of the German Ministry of Education and Research (Sustainable Land Management FKZ 033L004, Agricultural Systems of the Future - ZenKO FKZ 031B736, Urban-Rural Stadt-Land-plus ReGerecht FKZ 033L205) as well as a research and qualification project of TU Dresden. Selected parts of the article base on former work published as Zscheischler et al. (2012) as well as Härtel et al. (2015).

\subsection{Sustainable Communication in the Sciences}

Information and communication processes and the related content form an important basis for defining the principles of sustainable spatial development, at least since the 1992 United Nations Conference on Environment and Development in Rio de Janeiro. While forms of information provision and strategic use of communication are fundamental, renewed mediated information and communicative approaches have become widespread since the 1990s (Lievrouw et al. 2000). These can be applied fruitfully in different academic disciplines such as education or engineering, or in spatial planning and development processes (Weith et al. 2020). Respective information and communication technologies are now seen as part of different governance forms and are recommended for tackling various problems. For example, in 2003 the German Council for Sustainable Development initiated a "dialogue area" to strengthen understanding of processes of changing land use. Also the German federal government, whose goal was to reduce land use by settlement and infrastructure by 2020 to 30 hectares per day, began using such new communication instruments and triggered activity of further groups (even though the original timeline has meanwhile been extended to $2030^{1}$ ). While in a first step tools such as education material, brochures, cartoons, and computer games were produced to sensitize the relevant actors (Bock et al. 2009), in the almost two and a half decades toward the Sustainable Development Goals (SDGs) the focus has changed from information to knowledge management (Weith and Köhler 2019). Specifically knowledge management is addressed in three of the SDGs $(4,16$ and 17) and at the same time linked to education and lifelong learning. Digitization, although relevant for many goals, is explicitly addressed in sub-goal 9c (Industry, Innovation, and Infrastructure): "Significantly improve access to information and communication technology and ensure universal and affordable access to the Internet in the least developed countries by 2020" (United Nations 2015).

Non-governmental organizations (NGOs) such as the Nature Conservation Federation of Germany (Naturschutzbund Deutschland NABU), the Federation for the Environment and Nature Conservation Germany (Bund für Umwelt und Naturschutz

\footnotetext{
1 https://www.umweltbundesamt.de/themen/boden-landwirtschaft/flaechensparen-boeden-landsc haften-erhalten\#flachenverbrauch-in-deutschland-und-strategien-zum-flachensparen.
} 
Deutschland BUND), or the international World Wide Fund For Nature WWF now develop targeted campaigns to raise awareness and promote more sustainable use of natural resources. Initiatives such as the International Year of Biodiversity 2010, the International Year of Forests 2011, or the International Year Plant Health 2020 share mainly attempts to do this on an (inter)national level. Attention-grabbing activities must be taken rather frequently in efforts to change land use, because longterm changes do not have the direct "media marketing value" of disasters like the Fukushima tsunami in 2012. Against all communication efforts, discussion of topics such as soil conservation, land management, or the establishment of regional material cycles remains largely restricted to professional circles.

Despite comprehensive knowledge about communication theories and models, and especially about the concept of a sustainability communication, it can be stated that communication processes are not always effectively implemented. Today we may observe a pronounced awareness of sustainability in general and environmental issues in particular; in Germany, $64 \%$ of the population consider environmental and climate protection as an important challenge (BMU and UBA 2019) and the German Parliament may state in its 2019 Environmental Report that a "demanding environmental policy with effective environmental laws and competent environmental administrations is widely accepted by the population" (Deutscher Bundestag 2019, p. 4). Still there is a discrepancy between this awareness and individual behavior in Germany. For example, correlations of affect and cognition with environmental behavior are not particularly strong, but still substantial (r_aff $=0.51$ and $r \_c o g=$ 0.48). This means that people who agree with the affective and cognitive statements generally act more environmentally conscious (BMU 2019, p. 68).

In the view of the authors, this is due to the fact that the variety of existing means of communication are not used strategically and thus not exploited to their full potential (Kriese and Schulte 2009; Leipziger 2007). This is especially true in the "bulky" field of sustainability. The Sustainable Land Management (SLM) funding program of the German Federal Ministry of Education and Research (BMBF), described below, is used to critically investigate current practices in research and planning and to identify options for future activity. From 2008 to 2017, the BMBF initiated the SLM program to create a knowledge and decision-making basis for sustainable use of land resources. Already in designing the program the funder considered communication efforts as a central requirement for a successful implementation of this objective. This is only possible if all actors are willing to actually apply the new knowledge gained as a result of the program (Hinzen 2009). Targeted communication efforts played a central role in the management of inter- and transdisciplinary research networks of that funding scheme: It was a condition of information exchange, successful collaboration, and collaborative learning.

Successful communication not only creates awareness of new challenges, but also acceptance for new options, and may initiate behavioral change. It thus contributes significantly to the successful transfer and implementation of scientific findings into practice, in this case regarding the SLM program. But how can communication processes be designed in a targeted and successful way? How can existing knowledge of strategic communication sciences be linked to communicative requirements? How 
can means of communication be used strategically in such a complex field? What specific challenges have to be considered? And where are the limits of professional communication?

This paper presents some initial answers to these questions which were developed by one of the scientific projects accompanying the BMBF-funded SLM network. To achieve better insight, the authors first present the core topics of the network and then explain the role of communication in this context. Subsequently, specific challenges and influencing factors are discussed in order to finally outline a strategic approach.

\subsection{Theoretical and Conceptual Considerations for the Design of Communication Processes}

Human communication is a constant, every day, yet highly complex process that predominantly occurs unconsciously. It is social behavior at a time determined by many factors which accompany the message intendedly sent by a person. These factors include emotions, situational circumstances, and the knowledge and cognition abilities of the communication partners involved and its variety makes the communication process complex. In designing effective communication, it is therefore essential to be aware of the most important factors for the sender and the receiver; the latter include attention, the everyday ecology, and the personal and situational capacity (Kuckartz and Schack 2002). Moreover, communication is expected producing a social exchange of constructions, orientations, ideas, etc., about the world, exclusively created in social discourse and checked for their suitability (Frindte and Geschke 2019, p. 107). By social interaction those individual communications form entities of organizational character (Köhler 2014), which lead to an inter-institutional, i.e., external communication and exchange of knowledge, for example in networks.

Designing knowledge communication with external partners is a core activity of all research, especially of research networks. In science, such communication has been addressed only recently and is still considered as non-academic activity. In the age of online communication, this requires further special attention and skills (Köhler et al. 2019). With Web 2.0, communication technology shifts to a new social form in which content is produced jointly, incorporating all those interested in a certain topic even if they do not have scientific backgrounds. In a society defined by mass media, rivalry for the attention of various target groups is intense, so attracting attention to an issue may need to be the first step. To be perceived is a basic condition for successful communication. But this attention has consequences: Those who create attention must also create content. The term "everyday ecology" takes the real life of the recipient into account. Information may only have an impact if it has a meaning for the recipient, that is, if it can be linked to their real life. Strategic communications utilize this relationship to their advantage by considering the consequences, benefits, and options for the recipient, and presenting them consciously. Basically, a subject should not overwhelm a recipient or a target group. If they do not have the capacity to process 
a topic intellectually or emotionally, they may reject or avoid the information. All of these factors need to be analyzed and adapted to specific audiences. A communication strategy must therefore be adapted to the needs of the intended recipient. Senders have more options, which are determined by variables like authenticity, professionalism, and the available financial resources (ibid.).

The authenticity of a source is relevant to its visibility (Köhler 2016). Communication functions less on the level of the actual content than in terms of the type and way it is communicated. Credibility, competence, and empathy are the central determinants here. Increasingly, the communicator needs to be professional in order to compete for the "scarce resource" that is the attention of each target group. This professionalism includes organizational and technical know-how, knowledge about methodology, that is, how to address specific target groups, and practical experience. This can be achieved with further training and the help of external communications consultants or agencies.

Experience has shown that too often the only aspect of communication to be considered was the means, and that this was hardly ever strategically communicated (Kriese and Schulte 2009; Leipziger 2007). Recent findings focus on the need for human and financial resources as key to planning, designing, and implementing communication of innovations successfully (Pscheida et al. 2013). This means scheduling appropriate resources and setting goals for communication activities right from the beginning, at the initial planning stage of a research project. Yet, before the actual communicative tasks and related objectives are formulated, the means are often already fixed, usually without any consideration of whether they meet the purpose. Researchers and communicators need to consider the following questions: Is the chosen means useful in view of the objective? Which channel should be designed to address the target audience? What must be communicated and what must not? What steps need to be taken and in what order to achieve the goal?

\subsection{Knowledge Management in the Sustainable Land Management Program as a Challenge for External Communication}

The Sustainable Land Management program (SLM) had to meet a number of specific challenges toward developing an integrative communication approach. First, the organizational structure of the program was very complex (cf. Fig. 1). In more than two dozen collaborative projects and its 120 subprojects, scientists and practitioners from over 170 organizations were involved. The scientific disciplines involved in SLM brought very different perspectives, methods, and understandings to the overall SLM program. Unsurprisingly, science and practice often have different preferences, and thus communicative goals could be very heterogeneous. It is therefore obligatory to develop a comprehensive communication strategy that is accepted by the parties. 


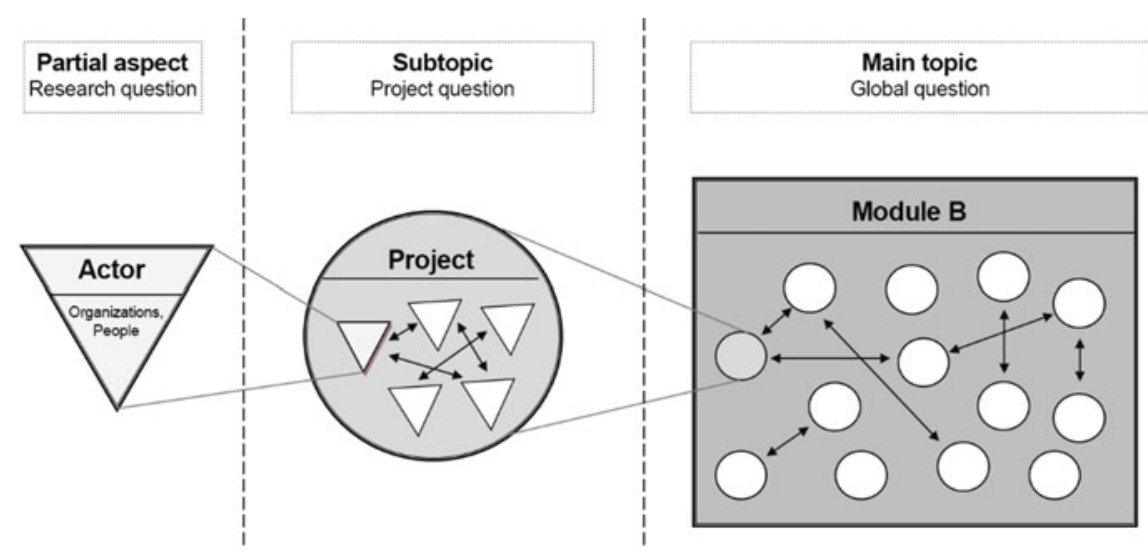

Fig. 1 Schematic representation of the network representing the funding program "Sustainable Land Management" (cf. Härtel et al. 2015; translated by authors)

Another challenge was to establish communication structures at the beginning of the program. In our case, a new organizational context with new communication channels needed to be defined and then perpetuated in the new SLM research network. This was time consuming and required resources, as individual experience from completed projects could not have been reused one to one. But this is a general challenge in science as nowadays, research is often project-based and short-term, that is, the organizational structures are frequently terminated and re-established again. Although bilateral or multilateral research and practice networks remain, the topic-overarching management structure, which includes integrated communication, usually dissolves. This is one reason why it is difficult to implement and perpetuate the results, knowledge, and experiences obtained. In addition, when research starts, the results are not yet available and cannot be presented quickly. But media products to be communicated must be developed first, i.e., cannot be finalized only when advertising needs to begin. At this stage, researchers are still developing models, principles, strategies, and combinations of instruments, which are complex and may be highly abstract. Accordingly, the "new" knowledge is owned only by a small group of experts only but has not been transferred to the target audience yet.

Further, SLM is an overarching term, so its actions are not clearly defined. Communications had to clarify what is meant by all three ambiguous and muchdebated parts of the term, "sustainability," "land," and "management." This means that all participants of the program had to deal with a high complexity and enormous variety of subjects. In fact SLM combined many issues which embody enormous communicative challenges. The collaborative projects, for example, were dedicated to sustainable water management, regional material and energy cycles, renewable resources, ecosystem services, sustainable urban development, and urban-rural linkages. The actors, interests, and target groups were also numerous. Thus, from a scientific point of view SLM is a highly complex field, which is typical for many research networks, especially for those that link research with its application in practice. 
Yet, mass media requires a high level of simplification, which is contrary to the claims of many scientists. They often have difficulty handling active (non-technical) media and do not want their highly complex topics to be reduced to simple, striking stories. This resonates with a common concern about losing their reputation in the scientific community. Scientists feel that they eventually lose control and sovereignty of interpreting their results through publication in the mass media. Black-andwhite arguments such as "renewable energy is positive" or "nuclear energy is bad" contradict not only the scientific, but also the communicative self-understanding of science. Due to that fear, scientists begin stepping into public in order to engage for their research, i.e., start acting as lobbyists. Respectively, they become aware to generate findings which may be associated with social consequences-what calls for a renewed consideration of research ethics (Dobrick et al. 2017) and can only be achieved with assessment based on normative values. Roose (2006) therefore speaks of an increasing politicization of science while Weingart (2001) points out the danger of its political exploitation.

Altogether, an intelligent communication strategy is required that centers on targeted but achievable action, even though very limited financial resources are available. Indeed communication for a typical research network like SLM cannot follow the rules of classic advertising because of the special funding conditions for such non-commercial topics. Yet, knowledge of the discussed key determinants of communication is essential. Therefore, in the following, the methodology for evaluating the most significant factors empirically is briefly introduced.

\section{Approach and Methodology}

\subsection{Data Collection}

Social science research objects and their stakeholders, as in the present case of the SLM funding program, are characterized through a complex and procedural context (Witzel 1985, p. 227). Following the research question, it was necessary to identify exemplary information transfer and implementation strategies within SLM funding program represented by the collaborative projects. The problem-centered interview was selected as the survey method to investigate the communication structures of the individual projects (Kaiser et al. 2012). We were interested in both internal and external transfer and implementation strategies. Twelve typical stakeholders concerned were interviewed, in order to collect their experiences and establish a systematic knowledge base. Following a qualitative approach, there was an equivalent consideration of both researchers and practitioners, covering all types of projects. In the course of the investigation, a research guide was developed as a basis for discussion, including aspects related to both content and communication. All researchers of the collaborative projects contributed to the guide, which covered all subject areas of interest regarding transfer and implementation. For the 
present analysis, the authors focused on the concept of transfer, and especially on communication-related aspects.

\subsection{Evaluation Method}

To analyze the interviews, the authors applied the qualitative method of content analysis developed by Mayring (2010), which can be used for communication text data. To cope with the length of the text and to serve the purpose of the problemcentered interviews, the authors decided to complete a structured content analysis. Guided by theory-based main categories, we systematically worked through the transcribed material and passages assigned to the categories.

By focusing on the transfer and implementation of knowledge in the project network and the resulting questions, main forms of practice can be concluded along the theory in a deductive way, forming main and sub-categories (see Härtel and Hoffmann 2013). In order to address the criterion of openness of the research process, the authors created an inductive category using the summary content analysis. Overall, the focus was on structured content analysis, in particular on structuring the content: "to filter out certain topics, content, aspects of the material and to summarize it" (Mayring 2010, p. 98).

The evaluation was conducted using the software MAXQDA. Specifically developed for structured content analysis, the software allows for the definition and use of codes and sub-codes which reflect the categories in an orderly manner (Kuckartz 2010, p. 114). Methodologically controlled compression of the material was used to work out cross-case statements on regularities in the terms of the research question (ibid., p. 110ff.).

\section{Results}

\subsection{Practitioners and Civil Society as Target Groups of External Knowledge Communication}

In the course of the interview analysis, we identified the target groups of external knowledge communication: These were practitioners in the economy, society, politics, and administration. Addressed economists often represented the agricultural and forestry sector; the former included the food manufacturing, and the latter the wood processing industry. Other practitioners were at the interface between the public and private sectors such as health care (doctors, health insurance), mobility and transport (transport networks), the energy sector, and the private education and research sector. Administrative practitioners covered a variety of responsibilities (municipal and state level) and subject matter including conservation, transport infrastructure, 
and health. Civil society actors, in a broader sense, included voluntary clubs and NGOs, such as nature conservation associations, support groups, and interest groups such as farmers' organizations.

\subsection{Effects and Interactions of Factors Influencing External Knowledge Communication}

Various aspects of inter-institutional, i.e., external knowledge communication (which we find in networks as well, going beyond bilateral exchanges) can be derived from the interviews, in terms of both content and process. First, the means of communication are selected with different intentions. Content includes project content and results usually developed for two reasons: to transfer knowledge from science to practice, and to provide feedback from actors during the research process. At the process level, it was observed that region and theme often influenced whether communicated content was picked up. Further, different practitioners often have different expectations on knowledge transfer. In the interview analysis, authors identified the following dimensions: efficiency in developing solutions and economy of the provided solutions (project results, scientific knowledge); practicability of the developed solutions to concrete problems or at least not making such problems worse (positive and negative movement between actors and researched problems); and the meaning of personal attitudes (in form of expectations regarding the research topic). These dimensions influence perception, acceptance of, and willingness for further communication in networks. The success of external knowledge communication is also affected by legal and statutory conditions, such as funding and copyright, the available human and financial resources, and scientists' capacity for such communication.

\subsection{Selecting a Suitable Means of Communication}

The available financial and human resources often limited the choices regarding means of communication in the collaborative projects. For example, limited resources hindered knowledge transfer between science and practice: "And then it was evaluated how expensive it is (...) and then it was determined that well that would surely exceed the budget" (Interview 1.1). Legal and statutory conditions had a similar effect: Privacy policies impeded access to the target group and restricted the means of communication. External communication needed to be adapted to the concerns of target groups, seasonal or other variations. "[W]e have always started public relations work in May, June, and not before, because [...] this is a seasonal theme, and you can't kindle a fire which keeps [burning] year round" (Interview 1.3). The general attitude of stakeholders, key players, and the audience to the project problem and results (e.g., environmentally sustainable agriculture and renewable energies) could 
impede or even prevent access to the target group, regardless of the means of communication used: "Of what avail is it, if the owner [of an agricultural land] tells you at the end (...): 'No, I don't like it because I have something against renewables anyway.' (...) There are some, very flat opinions" (Interview 2.9).

Obstacles related to the character of the actors have been found to be surmountable using appropriate means of communication. "And it takes a long time for these introverted groups. You can't hope at this moment. I have just spoken with one of them: 'Yes, yes, mhm, yes it's good'. And he didn't even say goodbye. And then you sit on the phone and think, 'What just happened?'” (Interview 2.5). It was in particular difficult to access practitioners who demonstrated a lack of trust. Reasons may include negative experiences in the past: "[T]his is certainly the downside we have in East [Germany], that people had pretty big security needs from the political system of the GDR [...] And today it is different and therefore people are sometimes overwhelmed and in certain places have been, I'd say, fooled, and that's why they tend to be careful" (Interview 2.9).

To reach as many people as possible and to give actors an insight into the status of the project, open-access publications were recommended: "You have to say that very clearly, this is a public [research] project, (...) so that we also see our obligation to make all our results publicly available. (...) [W]e want [the results] to actually be disseminated and accepted and we will then make the best possible information available to the public" (Interview 1.6). Direct face-to-face contact with the target audience could help too to identify representatives who could spread the message: "We went to the event and just talked with people. And at the agricultural fair you get very direct contact with the people. And, in fact, an assumption that I had proved to be correct. Namely, that a well-defined type of farmer [...] is the first who we can connect with" (Interview 2.5).

\subsection{Selecting and Preparing the Communications Content}

The content to be communicated has to meet the expectations of the target audience. In the course of the interviews, it came out that certain scientific project content, despite its practical relevance, was too complex and abstract for industry partners to see its relevance. Indeed, the wish was expressed that "the topic is somehow prepared either for the target group or scientifically [...] But, do not tell the whole world. Such a claim can only go wrong" (Interview 2.8). For scientists, this means "that science must speak increasingly in the language of the local partner when initiating contacts. So, not the language of science. [...] they need to translate for "the average Joe", (Interview 2.9).

Content prepared without a target group in mind, such as an exclusive scientific publication of project results, could "not reach all who work in practice" (Interview 1.6). For many actors, cost-effectiveness and efficiency are key criteria for the measure which is communicated. This may be a precondition for any dialogue with 
actors outside the scientific community. If project content or results are not considered economically or efficiently, it will be very difficult to communicate them to stakeholders. Certain topics in the field of SLM are perceived as "unattractive" or cannot be communicated easily to the wider public per se, such as the issue of short rotation coppice or biodiversity. This is often due to general attitudes of actors in the field of environmental sustainability.

If the impact of the project on a target group is expected to be negative, it is necessary to reflect on when and what content can be communicated: "The word 're-watering', that's what you say after a half-hour conversation. When people know that they will not be inundated. [...] You cannot come in with that" (Interview 2.5). Nevertheless, direct involvement can have positive effects, especially in the case of problems that would otherwise enjoy little attention or which create little incentive to generate scientific knowledge. This is true of non-tradable areas in the health sector: "My concern is conducive for health projects [...] if they are not able to be commercialized. I'm not talking about pharmaceutical development, where big profits attract attention but where it actually comes to service" (Interview 1.4). This partly precluded the need to prepare the project content, resulting in rather low commitment from scientists. "We collect the messages, see what is framed by this and then make a nice communication profile. What was the result? After two reminders came nothing at all. Only after a third, relatively nasty email [...], then came the usual suspects [...] the ones that had always made them anyways. And then we have with very full, very, very, very petty, very painstaking work somehow collected the messages. But now looking back, they were not really new messages. There were the usual messages" (Interview 2.8). When project outcomes have been prepared properly, focused on the target group by integrating a science journalist, the message reached people who can pass it on, such as journalists (Interview 1.5).

The content of external knowledge communication must be targeted to its audience to ensure successful knowledge transfer. In order for recommendations to be adopted in practice, it is important that "you very strongly address [...] the participants and pick them up thematically where they are anchored, that is, when I talk to a farmer who might not necessarily be interested in the depth of the bird world, but who cares more about the agricultural effects" (Interview 1.6).

Legal frameworks, such as copyright and intellectual property, can hinder knowledge transfer between science and practice, as certain technologies cannot be readily used by the practitioner: "There is a little problem: This is patented. One cannot simply be reconstructed, there are costs. But [...] it works, if constructed properly" (Interview 2.4).

Another hurdle for knowledge transfer was the profitability and efficiency expectations of practitioners. The cost of project results is even described as "the most inhibitory factor" (Interview 2.7) for successful knowledge transfer. This applies not only to economic practitioners but also local governmental ones, such as mayors. The latter could be encouraged to support and potentially pass the message on if they could identify potential for regional development: "because a small community in rural areas has to simply see what options are there to generate added value" (Interview 2.9). 


\subsection{Addressing the Attitude of Stakeholders}

Market conditions and industry policy often influence the attitude of stakeholders to problems, such as climate change adaptation in the food sector. It required special treatment of the content-differences and similarities must have been disclosed and potentials illustrated (see Interview 1.1). Some actors doubt whether the problem exists: "Is the climate really changing? So, are they telling us the right thing? And if they are not telling us the right thing, can I still do what I've been doing so far? Yes, they are easy and economic decisions ... decisions of habit: I have done it this way before, so why should I do it differently now? And you cannot answer that, you can just say, 'From OUR perspective if you do it, this and this will happen, and that and that will not happen, and you will have this and that risk"' (Interview 1.5). Another important factor in acceptance of research results and policy implications is vividness: "once it has something presentable. It is precisely what you can show this clientele - the farmers-something that is useful" (Interview 2.5). This may be "something photogenic" (Interview 2.5), but may also include specific transfer measures such as "field days." Events must specifically be relevant to the practitioners who attend, "but this being-on-site feeling and talking about it is what makes something. On that level I can facilitate the transfer easily when I create environments that are unusual" (Interview 2.5). The extent to which communication activities can be institutionalized successfully often depended on the available financial and human resources (Interviews 1.5 and 2.2).

The degree of concerns of target audience about the problem addressed in project has partly affected the communication with actors in a positive and negative way. Existing networks could simplify the access to the actors: "facing the transport sector was $[. .$.$] in many respects beneficial that they knew each other and that communica-$ tion then took place without problems" and "it was always a very good basis to get in contact with these target groups" (Interview 1.2). The means of communication thus became less relevant: "if now by email or [...] the better the connection is, the less important the communication means becomes and the more likely the success of communication" (Interview 1.2). Actors in a network make networking work: "if we have three, four who really want it in the county or district, that's enough. We don't need much more" (Interview 2.5). If it was in the interest of certain groups of actors to process a problem, this could encourage their commitment to successful knowledge transfer: "the local players participated because they also partly had a personal interest" (Interview 2.3). At the same time, actors did not give their support when a scientific problem has been considered irrelevant in practice: "without personal involvement, you may encounter limited interest. Because many other things are more important in the view of the people" (Interview 1.4). "Due to the positive development for farmers on the world market and also here in Germany for agricultural products, they are not dependent on this new product [...]. Everything is going well for him in the field. Why should he tackle these uncertainties?" (Interview 2.4). 
In general, different communication tools and channels, and how the content is revised, influence the potential for interacting with external knowledge communication. The analysis shows, the more specific and relevant to practice the content was, the more likely it was to get feedback from the addressed actors, because "people ask only if they know that they can ask. [...] You can only communicate that. Or I have a basket full of messages and can precisely position the target and target group" (Interview 2.8). For successful knowledge transfer to a wider public, acceptance and civil society participation was important: "you just involve people that are really objectively confronted with the background information. And people can simply decide what they, as it were, want. And then people can decide" (Interview 2.1). The potential for interaction was increased by extending the interfaces between the project researchers and the target audience, for example by including opinion leaders and key players on external project advisory boards.

Online media could increase the potential for interaction and facilitate target group feedback: "On our website we also get questions, requests for information. And so the messages that are received they have recorded. And [...] we hear, for example, that rental charges are a problem at the moment. And we take a look: so, does this really have an economic impact on this calculation, cost calculation, or is this actually a side issue, perhaps with a psychological effect, but has no economic meaning? And we grab the topics and try to then integrate them within our considerations and in our presentations" (Interview 2.4). Mere marketing efforts in external communication were not conducive, but rather direct exchange and regular contact with practitioners and key players: "We just don't do marketing. Instead we explain to them, we tell the tale. From our experience, from the first research results come conversations with practitioners. And then they share something" (Interview 2.5).

\section{Conclusions}

In order to cope with the variety of factors in communication processes and to keep a clear head, theorists from marketing and communication studies recommend a systematic approach with a specified sequence of operations, especially with a clear concept of how social media communication is embedded (cf. Leipziger 2007; Hansen and Schmidt 2010; Kreutzer 2018). Respective steps usually include an analysis of the current situation, the definition of the communicative tasks, the development of communication goals, the identification of target groups, the development of messages, and the designation of a strategy to implement the selected communication approach. To some extent such an approach matches the generic idea about implementing communication technologies into an organizational configuration in an ideal manner as developed by Munkvold (2003), who divides into four sub-areas of implementing collaboration technologies:

Organizational context;

Implementation project; 
Technological context;

Implementation phase.

Authors did previously explain how such can be transferred easily to the context of information exchange, learning and education (Köhler et al. 2010).

\subsection{Background and Communicative Tasks}

Sustainability communication is about to become a topic in scholarly publications at the intersection to citizen science practices (Weith and Köhler 2019), specifically, the influence of digitization on the genesis of knowledge in the context of a sustainable, fair development as discussed. In the context of land management, there is an overall strong focus on specific branches like tourism (Tiago et al. 2020). In any case that process begins with the collection of information describing the initial communication problem. As it is important to identify the significant data, this includes the consideration of relevant target groups and goals from the very beginning. Initially, only those facts relevant to communication problems are included. This process will identify communicative tasks that derive from the description of the initial situation and the necessity to modify or enhance communication actions. Its interpretation explores the problems to be solved, but does not yet offer solutions. In the specific case addressed here, the task is to identify how land users can most effectively acquire knowledge and develop a decision-making basis for SLM.

\subsection{Definition of Communication Objectives}

After analyzing the current situation and defining the communicative tasks, communication objectives should be formulated in a communication strategy. Objectives describe the desired end state of a process. Those are measurable and thus represent a kind of commitment. However, goals can change over the course of a project and then need to be adjusted.

Goal setters must ask whether the objectives can be reached at all. As well certain practices like the sustainability digital communication relationships are especially effective (Tiago et al. 2020). Of course unrealistic goals may not serve as appropriate, reliable basis for a successful communication concept. For example, including expensive measures within a modest budget will jeopardize the objectives. 


\subsection{Definition of Target Groups}

The more precisely a target group is defined, the better it can be addressed. This definition determines the communication tools and approach to be used. When identifying target groups, it can help to be guided by demographic, lifestyle-related, or functional factors (Hansen and Schmidt 2010). In some cases, target audiences may be divided into subgroups with different patterns of media reception (Fischer 2012). This information is used to decide how to access the target group. It should be noted that people play different roles, at work or at home, with family or friends.

A survey of collaborative projects in a workshop of the SLM network revealed that due to the wide range of actors relevant to the topic of land use, a variety of target groups exist. Some target groups could be clearly identified, such as stakeholders from management, agriculture, associations, academia, and research. Other target groups were described only very generally and imprecisely, such as "local people." This is problematic, in terms of selecting both the communication tools and content to be communicated.

\subsection{Formulating Messages}

Messages are content to be communicated to representatives of a target audience. The larger the target group selected, the simpler the messages should be. Such simple messages should consist only of models for everyday use. Complicated theoretical concepts have no place in the mass media, which presents a major challenge for scientists. It should be clear which effect model shall be implemented and why-if there is a marketing communication or an educational communication addressed. In a complex topic such as SLM with very different target groups and representatives on different levels of influence, it is also advisable to limit the selection of subjects and to focus on key contents. Such contents should contain only the most relevant information and consequences for the selected audience and the respective recipient. If the aim is behavioral change, the messages should present options for action.

\subsection{Definition of Communication Strategies}

The next step is to determine how to achieve the designated goals with the resources available. This means looking for the cheapest "lever" with which the target can be achieved most efficiently and effectively. The strategy combines all the resources for a specific parent maxim (Leipziger 2007). More recently, it is suggested that when analyzing sustainability communication a typology of three different communication modes would be appropriate: communication of, about, and for sustainability (Fischer 
et al. 2016). Obviously the SLM network applied all three dimensions simultaneously as these have been components of the developmental approach.

Well-known and frequently used approaches include the piggyback, testimonial, and provocation strategies (see Hansen and Schmidt 2010; Leipziger 2007). The aim of the piggyback strategy (also known as issue management) is to attach the desired message to a consistent public relations action or to current media issues. The testimonial strategy generates attention through celebrity ambassadors, and the provocation strategy seeks to attract attention by breaking taboos or challenging competitors. So far, our network has favored a piggyback strategy.

\subsection{Activity Planning and Scheduling (“Concerted Activity”)}

Only when the strategy has been defined does the implementation begin. Now is the time to clarify what measures will be taken when, where, and how often? An appropriate mix of measures is in line with the strategy and aims to attain the objectives set. Not every interesting idea is to become an appropriate measure. The results are an action and a schedule that represent all the measures in chronological order, the so-called communication plan. This becomes a management tool, provides an overview of all parties, and allows accurate budgeting.

However well thought out a plan may be, its implementation depends on many events which are not clearly predictable. There is the momentum of cross media communication as well as specific preferences of single stakeholders, especially in science, who are eventually not skilled for supporting social media communications (Pscheida et al. 2015; Albrecht et al. 2020). Resulting, delays can occur or journalists may suddenly no longer be interested in the subject because breaking stories take priority. Subsequently, deviations between plan and reality arise and one needs to respond promptly and derive new action consequences.

\subsection{Limitations of the Study}

The empirical data used for the study is limited to just one research network, in which stakeholders often share a single focus, embedded into a single domain. Even though the configuration of the network is overarching sectors and includes research as well as public administration as well as stakeholders from industry, its outreach is limited. Mainly representativity is hindered by the missing link to the individual citizen as well as the missing direct link to the media sector.

Additionally, the role of project advisory boards has not been addressed in detail, that is, political influence may overlap with other effects described. In this case, the direct involvement of the target group also increased the potential for interaction in the communication process. It would also have been possible to assess external knowledge communication needs by questioning the target group directly. Finally, 
authors did not explicitly address the presumably high potential for interaction offered by the concept of citizen science.

\subsection{Lessons Learned}

The study demonstrated that sustainable land management is a case which does have specific communicative affordances due to its complex, multi-actor character that brings together different perspectives. Still communication in and for research networks is not consequently addressed, literature both on practice and research is rather limited. Not only with the increasing meaningfulness of digital formats there is an increasing need for a well thought, analytically proven approach in designing communication of and within research networks strategically. Obviously scientists are not easily capable of developing such and are hindered first by their individual characteristics (limited competences skills, etc.) but as well by the ecological conditions (economic and structural deficits). In that sense the paper has collected theoretical and empirical evidence of how research may deal with the expectations toward the influence of (mainly digital) communications on the genesis of knowledge in the context of sustainable, fair development.

\section{References}

Albrecht, S., Minet, C., Herbst, S., Pscheida, D., Köhler, T.: The use of digital tools in scholarly activities. Empirical findings on the state of digitization of science in Germany, with special focus on Saxony. In: Koschtial, C., Köhler, T., Felden, C. (eds.) e-Science-The Enhanced Science. Progress in IS Series. Springer, Berlin (2020)

BMBF (Bundesministerium für Bildung und Forschung): Bekanntmachung der Richtlinien über die Fördermaßnahme Nachhaltiges Landmanagement, 24. Oktober 2008. https://www.bmbf.de/ foerderungen/13138.php (2008). Accessed 5 Apr 2020

BMU (Bundesministerium für Umwelt, Naturschutz und nukleare Sicherheit) \& UBA (Umweltbundesamt) (ed.): Umweltbewusstsein in Deutschland 2018. Ergebnisse einer repräsentativen Bevölkerungsumfrage. https://www.umweltbundesamt.de/sites/default/files/medien/1410/ publikationen/ubs2018_-_m_3.3_basisdatenbroschuere_barrierefrei-02_cps_bf.pdf (2019). Accessed 23 Jan 2020

Bock, S., Hinzen, A., Libbe, J. (eds.): Nachhaltiges Flächenmanagement—in der Praxis erfolgreich kommunizieren. Ansätze und Beispiele aus dem Förderschwerpunkt REFINA, Berlin (2009)

Deutscher Bundestag: Umwelt und Natur als Fundament des sozialen Zusammenhaltes. Umweltbericht 2019; Unterrichtung durch die Bundesregierung, Drucksache 19/13400. https://dip21.bun destag.de/dip21/btd/19/134/1913400.pdf (2019). Accessed 5 Apr 2020

Dobrick, F.M., Fischer, J., Hagen, L.M.: Research Ethics in the Digital Age: Ethics for the Social Sciences and Humanities in Times of Mediatization and Digitization. Springer, Berlin (2017). https://link.springer.com/chapter/10.1007/978-3-658-12909-5_6

Fischer, D., Luedecke, G., Godemann, J., Michelsen, G., Newig, J., Rieckmann, M., Schulz, D.: Sustainability Communication. (2016). https://doi.org/10.1007/978-94-017-7242-6_12 
Fischer, H.: Know your types-Konstruktion eines Bezugs zur Analyse der Adoption von ELearning-Innovation in der Hochschullehre; Doctoral Dissertation, TU Dresden/Uni Bergen (2012)

Frindte, W., Geschke, D.: Lehrbuch Kommunikationspsychologie. Beltz, Weinheim (2019)

Härtel, L., Hoffmann, M.: Transfer- und Implementierungsstrategien von Wissen im Projektverbund. Empirische Untersuchung am Beispiel der BMBF Fördermaßnahme Nachhaltiges Landmanagement. Forschungsbericht in Form einer Masterarbeit, TU Dresden: not published (2013)

Härtel, L., Hoffmann, M., Köhler T., Weith, T.: Wissenskommunikation und Transfer für die Landschaftsentwicklung. Eine Analyse im Forschungsnetzwerk „Nachhaltiges Landmanagement”. Zeitschrift für Gruppendynamik und Organisationsberatung 46, 289-312 (2015). https://doi.org/ 10.1007/s11612-015-0296-0

Hansen, R., Schmidt, S.: Konzeptionspraxis. Eine Einführung für PR- und Kommunikationsfachleute: mit einleuchtenden Betrachtungen über den Gartenzwerg. 5. Aufl. Frankfurter Allgemeine Buch, Frankfurt am Main (2010)

Hinzen, A.: Kommunikation und Bewusstseinsbildung. In: Bock, S., Hinzen, A., Libbe, J. (eds.) Nachhaltiges Flächenmanagement - in der Praxis erfolgreich kommunizieren. Ansätze und Beispiele aus dem Förderschwerpunkt REFINA. Berlin (2009)

Kaiser, D.B., Köhler, T., Weith, T.: Informations- und Wissensmanagement im Nachhaltigen Landmanagement (IWM im NLM). In: Köhler, T., Kahnwald, N. (eds.) Virtual Enterprises, Research Communities \& Social Media Networks. Proceedings of the GeNeMe 2012, pp. 121-133, Dresden (2012)

Köhler, T.: Patterns of inter-institutional and inter-organizational collaboration. Strengthening the relationship between VET and the labor market for developing a professional work force. In: Muslikhin, M., Surono, I.M. (eds.) Empowering Vocational Education and Training to Elevate National Economic Growth. Proceedings of the 3rd International Conference on Vocational Education and Training ICVET 2014, UNY Press, Yogyakarta (2014)

Köhler, T.: Visual anonymity in online communication. Consequences for creativity. In: Skulimowski, A.M.J. Kacprzyk, J. (eds.) Knowledge, Information and Creativity Support Systems: Recent Trends, Advances and Solutions. Springer, New York (2016)

Köhler, T., Neumann, J., Saupe, V.: Organisation des Online-Lernens. In: Issing, L.J., Klimsa, P. (eds.): Online-Lernen. Handbuch für Wirtschaft und Praxis. 2. Korrigierte Auflage. Oldenbourg Wissenschaftsverlag, München (2010)

Köhler, T., Schoop, E., Kahnwald, N.: Communities in New Media. Researching the Digital Transformation in Science, Business, Education \& Public Administration. Proceedings of 22nd Conference GeNeMe 2019. TUD Press, Dresden (2019)

Kreutzer, R.T.: Social-Media Marketing kompakt. Springer Gabler, Wiesbaden (2018)

Kriese, U., Schulte, P.: Flächenakteure zum Umsteuern bewegen! Analyse und Bewertung vorliegender Kommunikationsansätze - Ausgangspunkt für neue kreative Marketingstrategien. In: Bock, S., Hinzen, A., Libbe, J. (eds.) Nachhaltiges Flächenmanagement - in der Praxis erfolgreich kommunizieren. Ansätze und Beispiele aus dem Förderschwerpunkt REFINA, pp. 47-56. Berlin (2009)

Kuckartz, U.: Einführung in die computergestützte Analyse qualitativer Daten. VS Verlag für Sozialwissenschaften, Wiesbaden (2010)

Kuckartz, U., Schack, K.: Umweltkommunikation gestalten. Eine Studie zu Akteuren, Rahmenbedingungen und Einflussfaktoren des Informationsgeschehens. Leske + Budric, Opladen (2002)

Leipziger, J.W.: Konzepte entwickeln. Handfeste Anleitungen für bessere Kommunikation; mit vielen praktischen Beispielen. 2. Aufl. Frankfurter Allgemeine Buch im F.A.Z.-Inst., Frankfurt am Main (2007)

Lievrouw, L.A., Bucy, E., Frindte, W., Gershon, R., Haythornthwaite, C., Köhler, T., Metz, J., Sundar, S.S.: Current research in new media: an overview of communication and technology. In: Gudykunst, W. (ed.) Communication Yearbook 24. Lawrence Erlbaum Publishers, Mahwah (2000) 
Mayring, P.: Qualitative Inhaltsanalyse. Grundlagen und Techniken. Beltz, Weinheim (2010)

Munkvold, B.E.: Implementation and Use of Collaboration Technologies in a Multinational Engineering Group: The Case of Kvaerner. In: Munkvold, B.E. (ed.) Implementing Collaboration Technologies in Industry: Case Examples and Lessons Learned, pp. 109-128. Springer Verlag, Berlin (2003)

Pscheida, D., Köhler, T.; Mohamed, B.: What's your favorite online research tool? Use of and attitude towards Web 2.0 applications among scientists in different academic disciplines. In: Marsden, C., Tassiulas, L.: Proceedings of the 1st International Conference on Internet Science. Sigma Orionis, Brussels (2013)

Pscheida, D., Minet, C., Herbst, S., Albrecht, S., Köhler, T.: Use of social media and online-based tools in academia. Results of the Science 2.0-Survey 2014. https://nbn-resolving.de/urn:nbn:de: bsz:14-qucosa-191110. TUD Press, Dresden (2015)

Roose, J.: Lobby durch Wissenschaft. Umweltverbände und ökologische Forschungsinstitute im Vergleich. Online J. Environ. Policy Stud. (OJEPS) 1 (2006).

Tiago, F., Gil, A., Stemberger, S., Borges-Tiago, M.: Digital sustainability communication in tourism. J. Innov. \& Knowl. (2020). https://doi.org/10.1016/j.jik.2019.12.002

United Nations: Sustainable development goals. https://sustainabledevelopment.un.org/sdgs (2015). Accessed 5 Apr 2020

Weingart, P.: Die Stunde der Wahrheit? Zum Verhältnis der Wissenschaft zu Politik, Wirtschaft und Medien in der Wissensgesellschaft. 1. Aufl. Velbrück Wiss, Weilerswist (2001)

Weith, T., Barkmann, T., Gaasch, N., Rogga, S., Strauß, C., Zscheischler, J.: Sustainable Land Management in a European Context: A Co-design Approach. Springer, Berlin (2020)

Weith, T., Köhler, T.: Der Einfluss der Digitalisierung auf die Wissensgenese im Kontext einer nachhaltig-gerechten Entwicklung; Synergie. Fachmagazin für Digitalisierung in der Lehre, Ausgabe \#07, https://www.synergie.uni-hamburg.de (2019). Accessed 5 Apr 2020

Witzel, A.: Das problemzentrierte Interview. In: Jüttemann, G. (ed.): Qualitative Forschung in der Psychologie: Grundfragen, Verfahrensweisen, Anwendungsfelder, Beltz, Weinheim, pp. 227255, https://nbn-resolving.org/urn:nbn:de:0168-ssoar-5630, (1985)

Zscheischler, J., Weith, T., Gaasch, N., Strauß, C., Steinmar, R.: Nachhaltiges Landmanagement eine kommunikative Herausforderung. Flächenmanagement und Bodenordnung 5, 37-45 (2012)

Open Access This chapter is licensed under the terms of the Creative Commons Attribution 4.0 International License (http://creativecommons.org/licenses/by/4.0/), which permits use, sharing, adaptation, distribution and reproduction in any medium or format, as long as you give appropriate credit to the original author(s) and the source, provide a link to the Creative Commons license and indicate if changes were made.

The images or other third party material in this chapter are included in the chapter's Creative Commons license, unless indicated otherwise in a credit line to the material. If material is not included in the chapter's Creative Commons license and your intended use is not permitted by statutory regulation or exceeds the permitted use, you will need to obtain permission directly from the copyright holder.

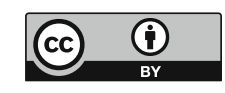

